\title{
Spatiotemporal Characteristics of Air Quality across Weifang from 2014-2018
}

\author{
Chengming Li, Zhaoxin Dai *, Lina Yang and Zhaoting Ma \\ Chinese Academy of Surveying and Mapping, Beijing 100830, China \\ * Correspondence: daizx@1reis.ac.cn
}

Received: 23 July 2019; Accepted: 23 August 2019; Published: 27 August 2019

\begin{abstract}
Air pollution has become a severe threat and challenge in China. Focusing on air quality in a heavily polluted city (Weifang Cty), this study aims to investigate spatial and temporal distribution characteristics of air pollution and identify the influence of weather factors on primary pollutants in Weifang over a long period from 2014-2018. The results indicate the annual Air quality Index (AQI) in Weifang has decreased since 2014 but is still far from the standard for excellent air quality. The primary pollutants are $\mathrm{O}_{3}$ (Ozone), $\mathrm{PM}_{10}$ (Particles with aerodynamic diameter $\leq 10 \mu \mathrm{m}$ ), and $\mathrm{PM}_{2.5}$ (Particles with aerodynamic diameter $\leq 10 \mu \mathrm{m}$ ); the annual concentrations of $\mathrm{PM}_{10}$ and $\mathrm{PM}_{2.5}$ show a significant reduction but that of $\mathrm{O}_{3}$ is basically unchanged. Seasonally, $\mathrm{PM}_{10}$ and $\mathrm{PM}_{2.5}$ show a U-shaped pattern, while $\mathrm{O}_{3}$ exhibits inverted U-shaped variations, and different pollutants also present different characteristics daily. Spatially, $\mathrm{O}_{3}$ exhibits a high level in the central region and a low level in the rural areas, while $\mathrm{PM}_{10}$ and $\mathrm{PM}_{2.5}$ are high in the northwest and low in the southeast. Additionally, the concentration of pollutants is greatly affected by meteorological factors, with $\mathrm{PM}_{2.5}$ being negatively correlated with temperature and wind speed, while $\mathrm{O}_{3}$ is positively correlated with the temperature. This research investigated the spatiotemporal characteristics of the air pollution and provided important policy advice based on the findings, which can be used to mitigate air pollution.
\end{abstract}

Keywords: air quality index; primary pollutants; temporal characteristics; spatial characteristics; Weifang

\section{Introduction}

Since the Chinese economic reform, with the rapid industrial development and growing energy consumption in China, air pollutant emissions have increased continuously, thus exacerbating air pollution. For example, in January 2013, a wide range and long duration of hazy weather occurred in Central and eastern China, raising public concern about urban air quality [1-3]. To address more serious air pollution, the Chinese government announced the new National Ambient Air Quality Standards in 2012 and completed all-round monitoring of air quality in cities at the prefecture level in 2015. By 2016, air quality monitoring was implemented in 338 cities in China. Air pollution can cause respiratory, cardiovascular, and cerebrovascular diseases through gas exchange in the lungs $[4,5]$. Air pollution also reduces atmospheric visibility and causes smog [6,7] and inconvenience to travelers. Therefore, it is critical to accurately identify the temporal and spatial characteristics of air quality and its main influential factors and to correspondingly control and alleviate air pollution.

At present, existing research on the temporal and spatial characteristics of air quality can be classified into three types: Studies based on remote sensing inversion of the aerosol optical depth (AOD), studies based on ground monitoring stations and studies based on modelling which is complementary to satellite and ground-based observations; Studies based on remote sensing inversion usually focus on large-scale areas to provide a regional overview [8]. Due to the high frequency monitoring, research based on real-time ground-monitored data is significant to better explore the detailed patterns (seasonal, 
and diurnal) especially at the city scale, for instance, for medium- and small-scale areas. This study focuses on the analysis based on ground-monitored data.

Many previous studies focused on the spatiotemporal characteristic analysis of air pollution in large-scale regions. For example, Zhan et al. [9] analyzed the AQI in 338 cities in China and revealed that air pollution in China was still serious in 2015, with $\mathrm{PM}_{2.5}, \mathrm{PM}_{10}$, and $\mathrm{O}_{3}$ being the primary pollutants, and the temporal and spatial characteristics were observed to differ in various cities. Using ground monitoring data, Zhao et al. [10] analyzed the temporal and spatial variations in $\mathrm{PM}_{2.5}$, $\mathrm{PM}_{10}, \mathrm{SO}_{2}$, and $\mathrm{NO}_{2}$ in five areas, namely, the Yangtze River Basin, the Bohai Economic Rim, the Pearl River Delta, the Central Urban Agglomeration, and the Western Urban Agglomeration, and the results indicated that since 2013, the concentrations of most pollutants decreased. Yan et al. [11] conducted statistical analyses on the $\mathrm{PM}_{2.5}$ concentrations in 13 cities in the Beijing-Tianjin-Hebei region in 2016 and found that the $\mathrm{PM}_{2.5}$ concentration was the highest in Winter (December-February) but the lowest in Summer (June to August). Spatially, the $\mathrm{PM}_{2.5}$ concentration was higher in cities far away from the Bohai Bay, but lower in coastal cities. Hu et al. [12] analyzed the temporal and spatial characteristics of the $\mathrm{PM}_{2.5}$ and $\mathrm{PM}_{10}$ concentration distributions in 33 cities in the North China Plain and the Yangtze River Delta based on hourly particulate matter (PM) concentration data from January-August 2013. The results suggested that the $\mathrm{PM}_{2.5}$ concentrations in these two regions exceed the standard of the World Health Organization (WHO), and higher proportions of coarse-grained particles are found in these regions [12].

With respect to studies on small analytical units, based on nine national monitoring stations, Chen et al. [13] discovered that the $\mathrm{PM}_{2.5}$ concentration in Nanjing varies significantly seasonally, and the $\mathrm{PM}_{2.5}$ concentration is the highest in Winter but the lowest in Summer, while the peak concentration is higher at night than that during the day. Based on research on 10 national PM monitoring stations in Gansu in 2014, Guan et al. [14] pointed out that the $\mathrm{PM}_{10}$ concentration is the highest in March in Gansu because of frequent springtime sandstorms, while the $\mathrm{PM}_{2.5}$ concentration reaches its peak in January due to home heating. Zhao et al. [15] reported that cities in the southwestern part of the Sichuan Basin have higher change rates of the $\mathrm{PM}_{2.5}$ concentration compared to other cities by analyzing the daily $\mathrm{PM}_{2.5}$ concentrations from 22 ground monitoring stations, and the researchers indicated that the $\mathrm{PM}_{2.5}$ concentration is negatively correlated with the boundary layer height and wind speed but positively correlated with the air temperature. $\mathrm{Xu}$ et al. [16] showed that the annual average $\mathrm{PM}_{2.5} / \mathrm{PM}_{10}$ ratios in urban areas have distinct seasonal, monthly, and daily variation patterns; the ratios increase significantly along the spatial gradient from the rural areas and the boundaries of the urban areas to the core regions of the cities.

However, due to the incomplete ground monitoring data and the complication of processing of a very large amount of long-term data, there are limitations in the state-of-the-art similar studies. First, most studies focused on typical and large-scale regions, like Beijing-Tianjin-Hebei $[17,18]$ and the Yangtze River Delta [19], with little research paid attention to small-scale areas, especially in heavily polluted Weifang City [20]. Furthermore, studies mostly focused on only a single pollutant, such as $\mathrm{PM}_{2.5}$ or $\mathrm{PM}_{10}$, but people are seldomly exposed to a single pollutant [12], and analysis of various pollutants is more valuable. Third, studies mostly used approximate and historical data from nationally controlled monitoring stations (fewer than 20 in number when focusing on one city), leading to low spatial resolutions; moreover, the existing studies mostly used daily data during short periods (such as one year), resulting in low temporal resolution.

These limitations motivate this study. This paper uses hourly high-frequency ground monitoring data from 38 national and provincial monitoring stations in a heavily polluted city, Weifang, from 2014-2018, and adopts efficient statistical methods, such as frequent pattern mining, to comprehensively explore the temporal and spatial characteristics of the AQI and the primary pollutants in the city. The objectives of this paper are: (1) to analyze for the first time the characteristics of AQI during a long period from 2014-2018 in Weifang City; (2) to explore the spatial-temporal patterns of primary pollutants influencing the AQI in Weifang City; and (3) to assess the correlations 
between primary pollutants and meteorological factors quantitatively. This paper helps to improve the understanding of the temporal and spatial characteristics and the mechanisms of air pollution in Weifang City, and can provide scientific and technical support for subsequent air pollution research. Furthermore, the study helps to formulate effective prevention and control measures and offers policy advice specifically for environmental management in Weifang and other similar areas.

This paper includes four sections. Section 2 describes data sources and methodologies. The temporal and spatial characteristics and the influential factors of the air quality in Weifang are explained in Section 3, followed by the conclusions in Section 4.

\section{Data and Methods}

\subsection{Study Area and Data}

\subsubsection{Study Area}

Weifang City is located in the middle of the Shandong Peninsula (Figure 1), with Zibo City to the west, Linyi City to the south, Qingdao to the east and Laizhou Bay, Bohai Sea, to the north, between $118.17^{\circ} \mathrm{E}-120.01^{\circ} \mathrm{E}$ and $35.68^{\circ} \mathrm{N}-37.43^{\circ} \mathrm{N}$. The study area includes four districts, six cities and two counties, with a total area of $16,000 \mathrm{~km}^{2}$. Weifang City is high in the south and low in the north. The southern part is dominated by low hills, while the northeastern part consists of mainly plains, bays and rivers. Weifang is a semihumid area with a temperate continental monsoon climate. In 2018, Weifang was one of the most rapidly developing cities in Shandong Province. There have been rapid advancements in various fields, such as industry, transportation, and economy. However, the air pollution that comes with these developments has become increasingly serious. The air quality of the city is slightly below average compared to both those of other cities in Shandong and those of key cities in China. Nevertheless, there are few studies and reports on different air pollution indicators in Weifang. Investigation and analysis of the temporal and spatial characteristics of air pollutants are therefore important for improving the air quality in Weifang.

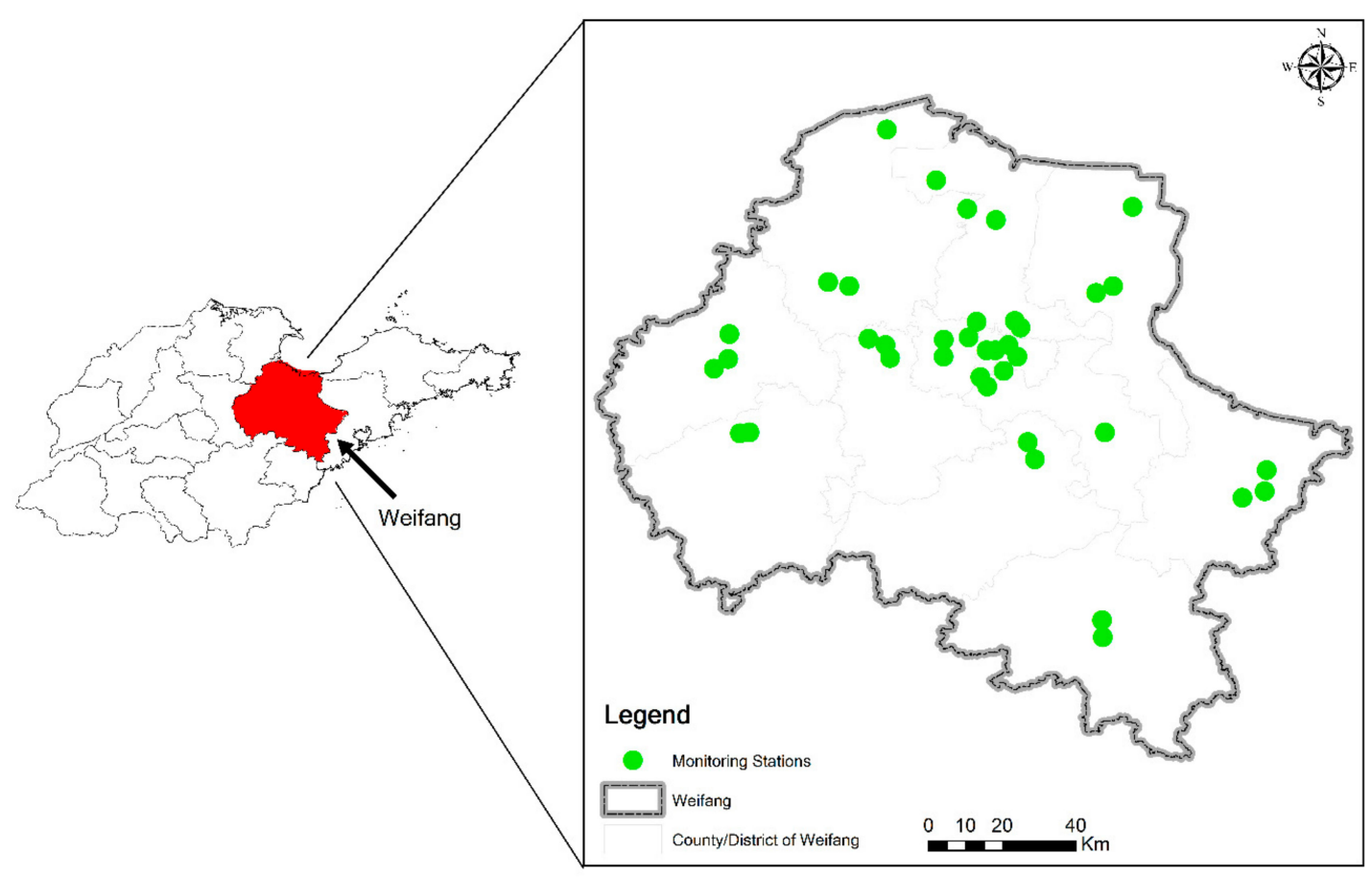

Figure 1. Study area and spatial distribution of the 38 monitoring stations in Weifang. 


\subsubsection{Data Sources}

The monitoring station data used in this study were obtained from 5 national stations, 4 provincial stations, and 29 urban stations in Weifang and included six air pollutants, namely, coarse particulate matter $\left(\mathrm{PM}_{10}\right)$, fine particulate matter $\left(\mathrm{PM}_{2.5}\right)$, ozone $\left(\mathrm{O}_{3}\right)$, nitrogen dioxide $\left(\mathrm{NO}_{2}\right)$, sulfur dioxide $\left(\mathrm{SO}_{2}\right)$, and carbon monoxide $(\mathrm{CO})$. Data are retrieved by the monitors every five minutes. All the data used in this paper are in units of hours, which are calculated as the average of the measurements taken every five minutes. The meteorological data used in this paper are from the Weifang Statistical Bulletin, including the wind speed and air temperature.

The AQI is a dimensionless index that quantitatively describes the air quality. According to the new National Ambient Air Quality Standards (GB 3095-2012) implemented by the Ministry of Environmental Protection (now known as the Ministry of Ecology and Environment) of the People's Republic of China in 2012, different individual air quality indices (IAQIs) of various factors ( $\mathrm{PM}_{10}$, $\mathrm{PM}_{2.5}, \mathrm{O}_{3}, \mathrm{NO}_{2}, \mathrm{SO}_{2}$, and $\mathrm{CO}$ ) are first computed, and then the highest IAQI value is taken as the value of the AQI. The equation is given as follows.

$$
\begin{aligned}
& I A Q I_{p=} \frac{I A Q I_{H i}-I A Q I_{L o}}{C_{H i}-C_{L o}}\left(C_{p}-C_{L o}\right)+I A Q I_{L o} \\
& A Q I=\max \left(I A Q I_{1}, I A Q I_{2}, I A Q I_{3}, \ldots, I A Q I_{n}\right)
\end{aligned}
$$

When AQI $>50$, the factor with the highest IAQI represents the major pollutant. There are six AQI categories, and their ranges are $0-50,51-100,101-150,151-200,201-300$, and $>300$. The corresponding pollution levels are excellent, good, lightly polluted, moderately polluted, heavily polluted, and severely polluted, respectively. The higher the AQI, the worse the air quality becomes [21].

\subsection{Data Processing}

Up to 10 million air quality data points are used in this paper. Traditional Geographical Information System (GIS)-based statistical analysis methods cannot satisfy the processing of a large amount of data. To achieve efficient calculations and analyses and to allow interactive visualization of the temporal and spatial characteristics of the air pollutants, the frequent pattern (FP)-growth algorithm is used in this paper [22].

The FP-growth algorithm is an FP mining algorithm based on the FP-tree structure. FP-tree structure is an extended prefix-tree structure for storing compressed, crucial information about frequent patterns. The basic idea of this algorithm is as follows. First, for each item, its conditional projection database and projection FP-tree are constructed. Then, this process is repeated for each newly built FP-tree until the constructed new FP-tree is empty or contains only one path. Finally, when the constructed FP-tree is empty, its prefix is frequent pattern.

The FP-growth algorithm can improve efficiency of mining with techniques as follows. By preserving key information of each set, a large database in the transaction database is compressed into an FP-tree, which can avoid costly, repeated database scanning. Furthermore, a partitioning-based method is used to decompose the mining task into a set of smaller tasks for mining confined patterns in conditional databases, which dramatically reduces the search space [22]. The FP-growth algorithm utilizes tree structures to compress transactions, which greatly enhances the efficiency for a large amount of data processing [23]. Han et al. reported that the FP-growth method is efficient and scalable for mining both long and short frequent patterns, and is about an order of magnitude faster than the Apriori algorithm [22]. This paper employs the FP-growth algorithm based on the Spark platform.

A valid check on hourly data was conducted to eliminate problematic and missing data points before data processing tasks. Statistical analysis and ArcGIS are used to explore the temporal and spatial patterns of air pollution. For temporal statistical analysis, $\mathrm{C}++$ language is applied in this study to obtain annually, seasonal, monthly, and daily variations of air pollutants; these variations are calculated by the arithmetic means of the hourly renewed data from 38 ground monitoring stations 
from 2014-2018. For spatial analysis, spatial characterization is conducted through the use of spatial analysis methods with the support of ArcGIS software (published by the Environmental Systems Research Institute (ESRI), Redlands, California, USA).

\section{Results and Discussion}

\subsection{Urban Air Quality in Weifang}

\subsubsection{AQI Characteristics}

Figure 2 shows the variation characteristics of the annual average AQI in Weifang from 2014-2018. The figure indicates that the AQI in Weifang is high. From 2014-2017, the AQI is higher than 100, which is slightly polluted. Specifically, the air pollution in Weifang is serious in 2014, with an average AQI of 124. In subsequent years, the value decreases, with a decrease of $20.16 \%$. However, the value is still far from the standard for excellent air quality, where AQI $<50$. The decreasing trend may be closely related to the environmental protection actions taken under the eight major initiatives, including controls on pollution from industry, fossil fuel consumption, and motor oil and gas consumption in 2017.

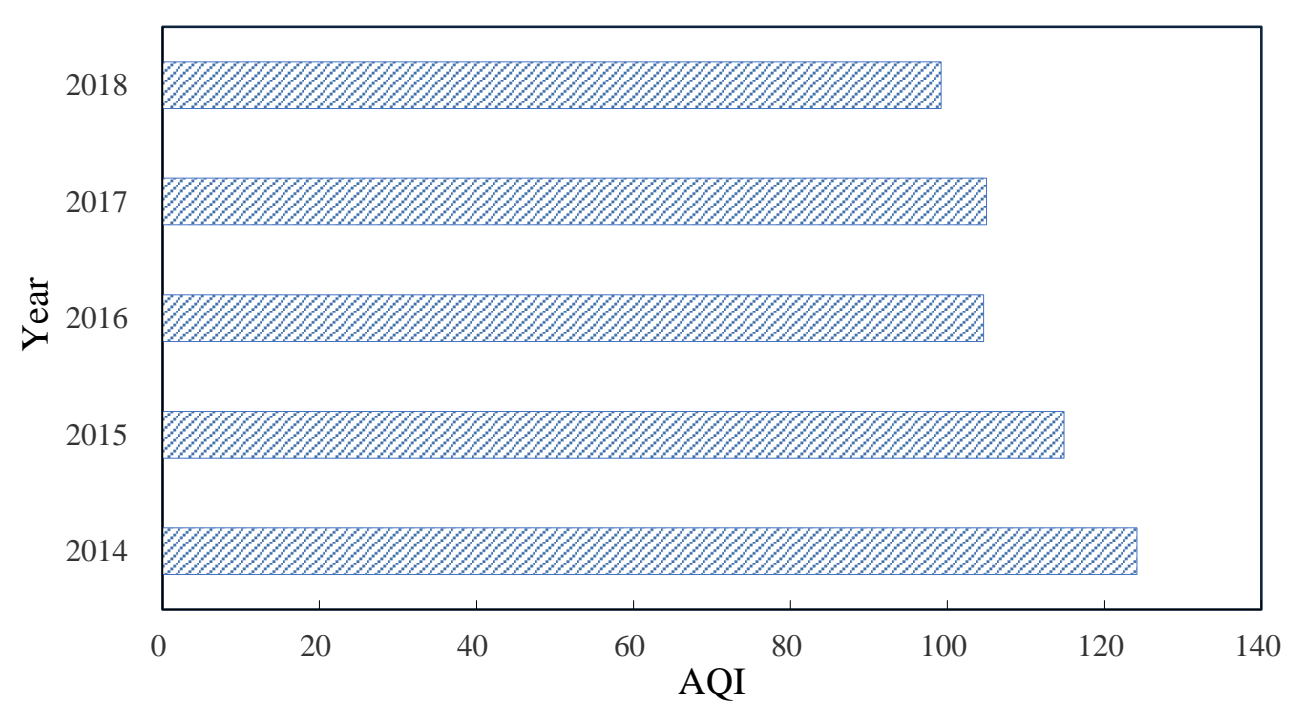

Figure 2. Annual average of the AQI in Weifang from 2014-2018.

Figure 3 illustrates the proportions of days with different AQI categories in Weifang from 2014-2018. In the past five years, the proportion of days with excellent and good air quality to the total number of days has gradually increased. The proportion reaches $60 \%$ in 2018 , but there is still a gap between this value and the expected value of $80 \%$ of the Chinese government. The number of days when the city is slightly polluted decreases gradually from 2014-2017, but the number of slightly polluted days rises slightly in 2018. The number of days when the city is heavily or severely polluted significantly decreased by $20 \%$ in 2018 compared to 2014 . However, there are still days when the city is severely polluted.

The variations in the daily average AQI in Weifang from 2014-2018 are shown in Figure 4. There are certain periodic characteristics, with five U-shaped distributions. From 2014-2018, the number of days when the AQI falls in the second category (good air quality) is the greatest, accounting for approximately $49 \%$ of the total days. Days with good air quality $(51<\mathrm{AQI}<100)$ are often found in July, August, and September. This phenomenon is because pollutant diffusion and dilution are more favorable when precipitation and vegetation coverage increase, and surface convection becomes stronger in Summer. The number of days when the AQI falls in the slightly polluted level ranks second $(29 \%)$. The number of days with moderate pollution accounts for approximately $12 \%$, while those with 
$\mathrm{AQI}>200$ (heavy and severe pollution) account for approximately $5 \%$ of the total days. The days with heavy and severe pollution occur mostly in January, November, and December, which is consistent with many other studies $[9,24]$. This finding may be because the meteorological conditions in Winter, such as frequent temperature inversion, low air temperatures, weak convection, little precipitation, and low humidity, do not facilitate air movement in Weifang. Furthermore, heating during Winter leads to a surge in fossil fuel consumption and thus increased emissions of pollutants [25]. In summary, the AQI in Weifang is high in Winter and low in Summer.

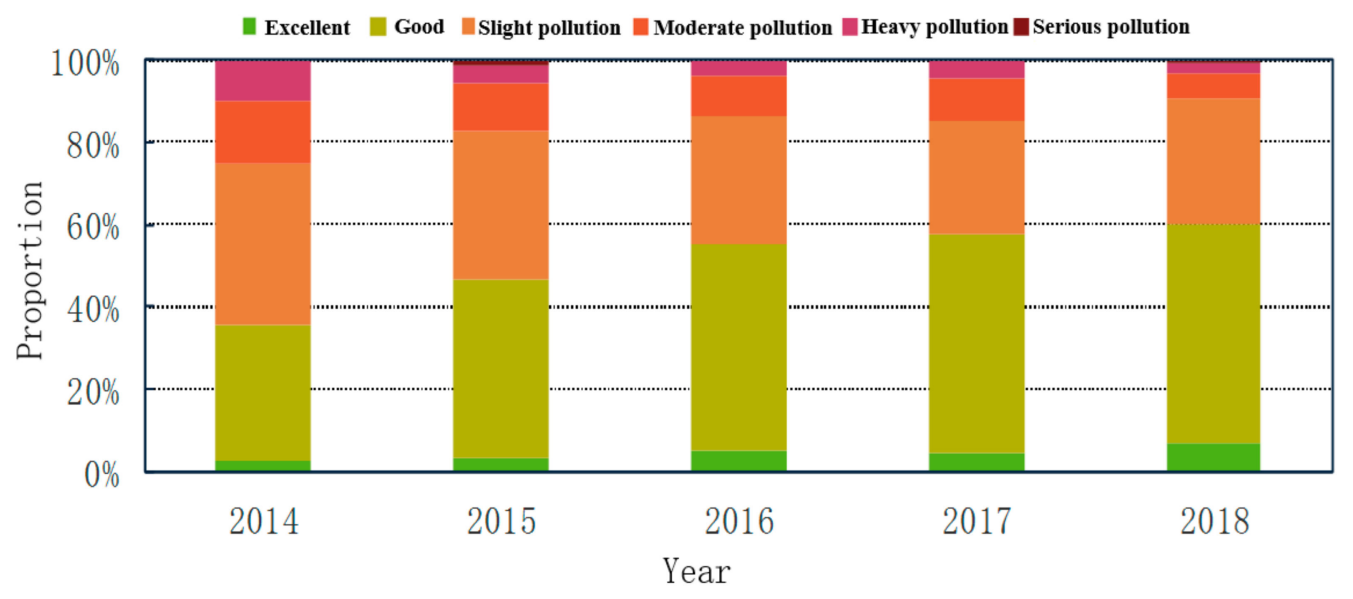

Figure 3. Statistical analysis of the different AQI categories from 2014-2018 in Weifang.

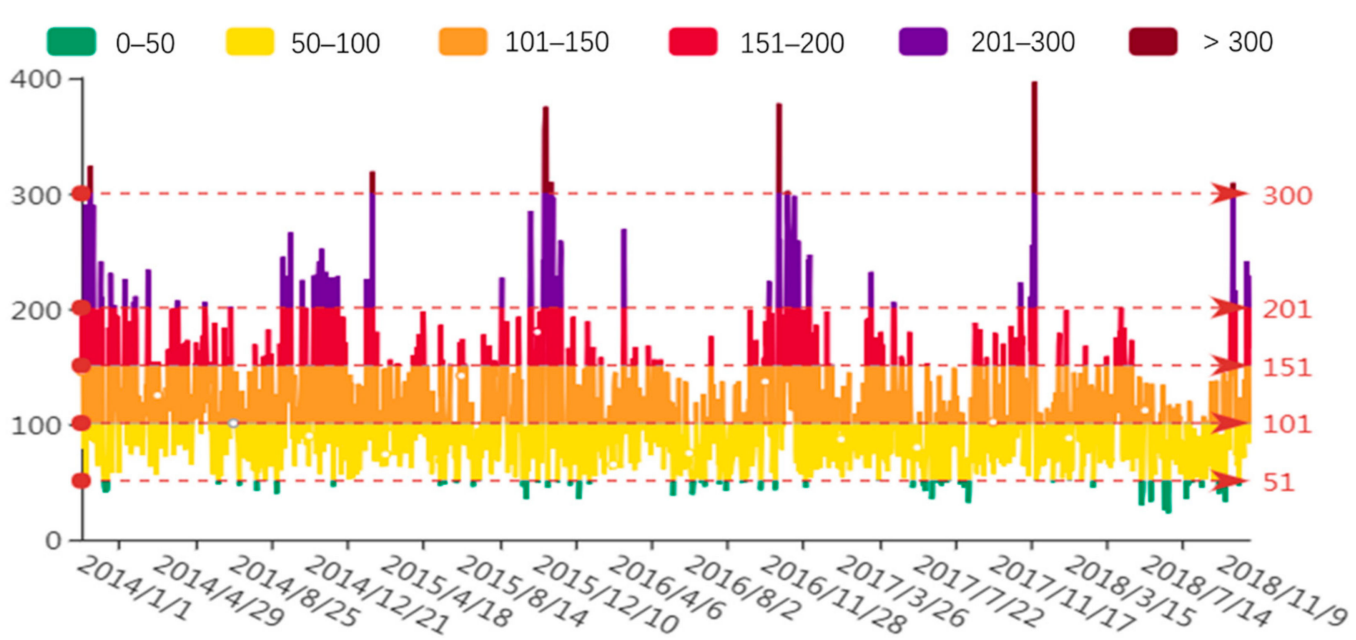

Figure 4. Variations in the daily average AQI in Weifang from 2014-2018.

\subsubsection{Primary Pollutants Affecting the AQI in Weifang}

Statistical analyses are conducted to calculate the proportions of days when different pollutants become the major pollutants in Weifang (Figure 5) in 2018. The results demonstrate that the number of days when $\mathrm{O}_{3}$ is the major pollutant in the city is the greatest (148 days) and accounts for approximately $40.55 \%$ of the total days, followed by $\mathrm{PM}_{10}$ and $\mathrm{PM}_{2.5}$, with percentages of $31.25 \%$ and $20.82 \%$, respectively. However, the days when $\mathrm{NO}_{2}, \mathrm{SO}_{2}$, and $\mathrm{CO}$ are the major pollutants account for only $7.67 \%$ of the total days. This finding is similar to the conclusions of Zhan et al. [9] and Song et al. [26], who performed AQI analyses across China and discovered that $\mathrm{PM}_{2.5}, \mathrm{PM}_{10}$, and $\mathrm{O}_{3}$ are the major air pollutants. However, the proportion of days when $\mathrm{PM}_{2.5}$ is the major pollutant is the highest for mainland China and that of $\mathrm{O}_{3}$ is the highest in Weifang [26]. 


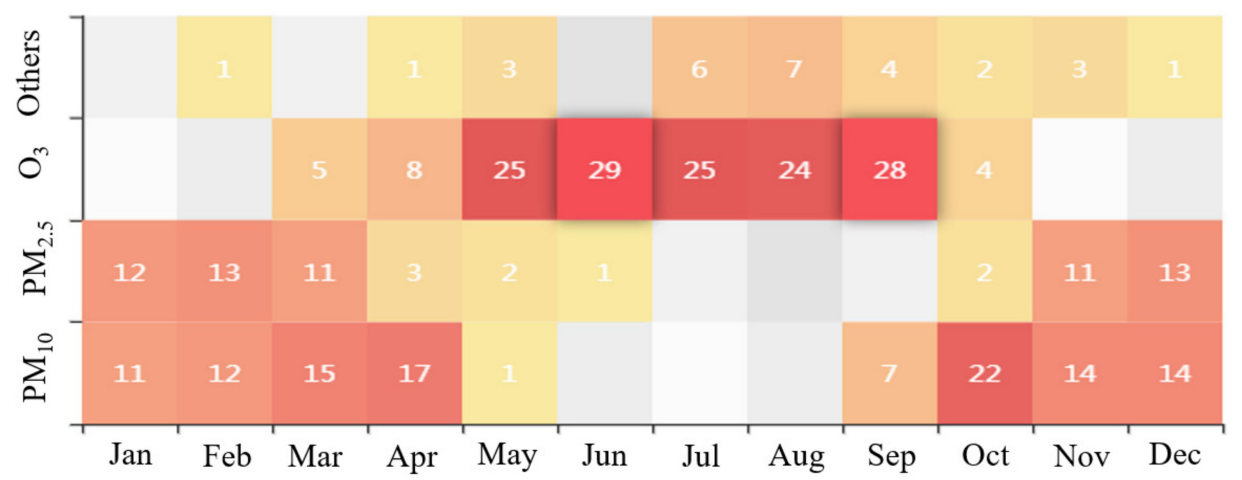

Figure 5. Frequency of the different pollutants being the primary pollutant in the different months.

To more specifically analyze the mechanisms affecting the air quality in Weifang, this paper evaluates the temporal and spatial characteristics of the top 3 primary pollutant $\left(\mathrm{O}_{3}, \mathrm{PM}_{10}\right.$, and $\left.\mathrm{PM}_{2.5}\right)$ that affect the AQI separately.

\subsection{Temporal Characteristics of the Primary Pollutants}

\subsubsection{Annual Characteristics}

Figure 6 shows the annual average concentrations of the six pollutants in Weifang from 2014-2018. The annual average $\mathrm{PM}_{10}$ concentration in 2018 is $107.3 \mu \mathrm{g} / \mathrm{m}^{3}$, which is $38.22 \mu \mathrm{g} / \mathrm{m}^{3}$ lower than that in 2014 , with a percentage decrease of $26.3 \%$. In addition, compared to that in 2014 , the annual average $\mathrm{PM}_{2.5}$ concentration in 2018 decreased by $29.59 \mu \mathrm{g} / \mathrm{m}^{3}$ (35.4\%) and reached $53.99 \mu \mathrm{g} / \mathrm{m}^{3}$. Nevertheless, the annual average $\mathrm{PM}_{2.5}$ concentration still exceeded the grade II standard of the Chinese Ambient Air Quality Standards (CAAQS) $\left(35 \mu \mathrm{g} / \mathrm{m}^{3}\right)$. Unlike the PM concentration cases, the concentrations of $\mathrm{O}_{3}$ always remain at high levels from 2014-2018 and exceed the national first-level standard $\left(100 \mu \mathrm{g} / \mathrm{m}^{3}\right)$. Unlike haze, $\mathrm{O}_{3}$ pollution is not visible, resulting in neglect. However, excessive intake of $\mathrm{O}_{3}$ can cause lung failure. The government and citizens should pay more attention to $\mathrm{O}_{3}$ pollution and take effective measures to alleviate $\mathrm{O}_{3}$ pollution [26,27].

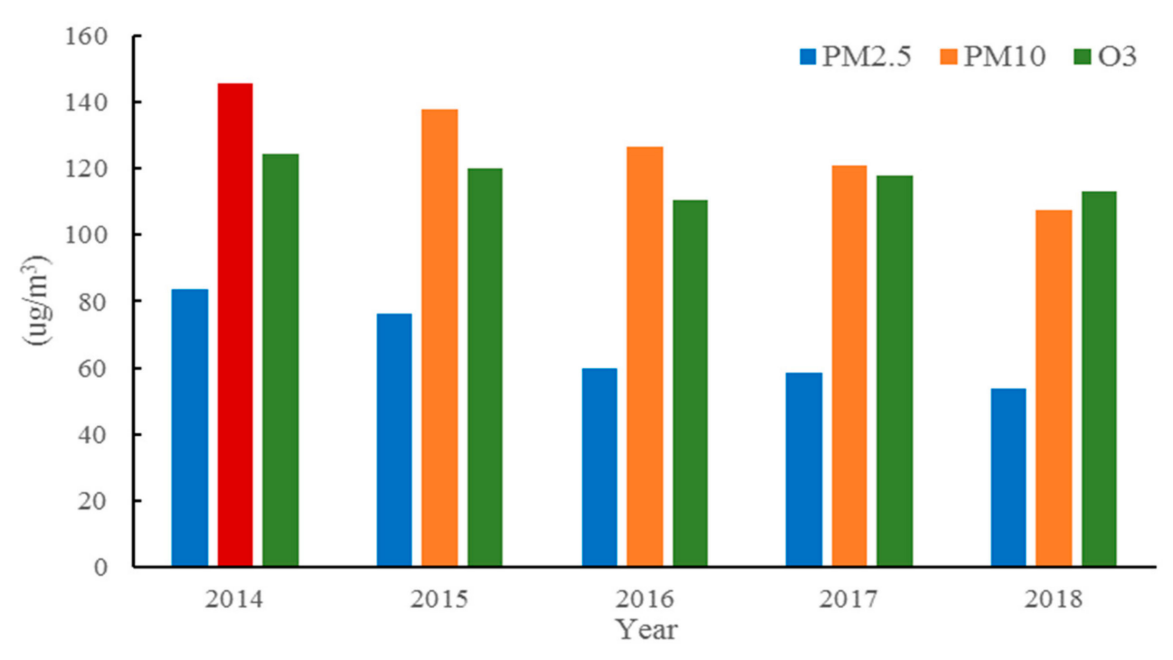

Figure 6. Annual average concentration of the pollutants that affect the AQI in Weifang.

\subsubsection{Seasonal and Monthly Characteristics}

The statistical seasonal and monthly characteristics of the primary pollutants in Weifang are illustrated in Figures 7 and 8, respectively. In Winter, $\mathrm{PM}_{2.5}$ and $\mathrm{PM}_{10}$ are the primary pollutants. In Summer, $\mathrm{O}_{3}$ becomes the major pollutant, followed by $\mathrm{PM}_{10}$. Specifically, the annual peak of the 
daily maximum 8-hour concentration of $\mathrm{O}_{3}$ is found in summer, and the maximum concentration occurs in June. An annual trough appears in Winter, and the minimum concentration is reached in January and December. This phenomenon results in a distinct inverted U-shaped variation curve with seasonal $\mathrm{O}_{3}$ concentrations in the ascending order of winter $>$ spring $>$ autumn $>$ summer. In contrast to the monthly $\mathrm{O}_{3}$ variations, the variations in the $\mathrm{PM}_{2.5}$ concentrations follow a distinct U-shaped curve. A trough appears in summer, which agrees well with previous studies [28,29]. The minimum concentration normally occurs in August, whereas the maximum is reached in January and December. The seasonal $\mathrm{PM}_{2.5}$ concentrations follow the ascending order of summer $>$ autumn $>$ spring $>$ winter. The $\mathrm{PM}_{10}$ variations are similar to those in $\mathrm{PM}_{2.5}$, but the $\mathrm{PM}_{10}$ trough occurs in autumn, and the seasonal $\mathrm{PM}_{10}$ concentrations can be arranged in the ascending order of autumn $>$ summer $>$ spring $>$ winter.

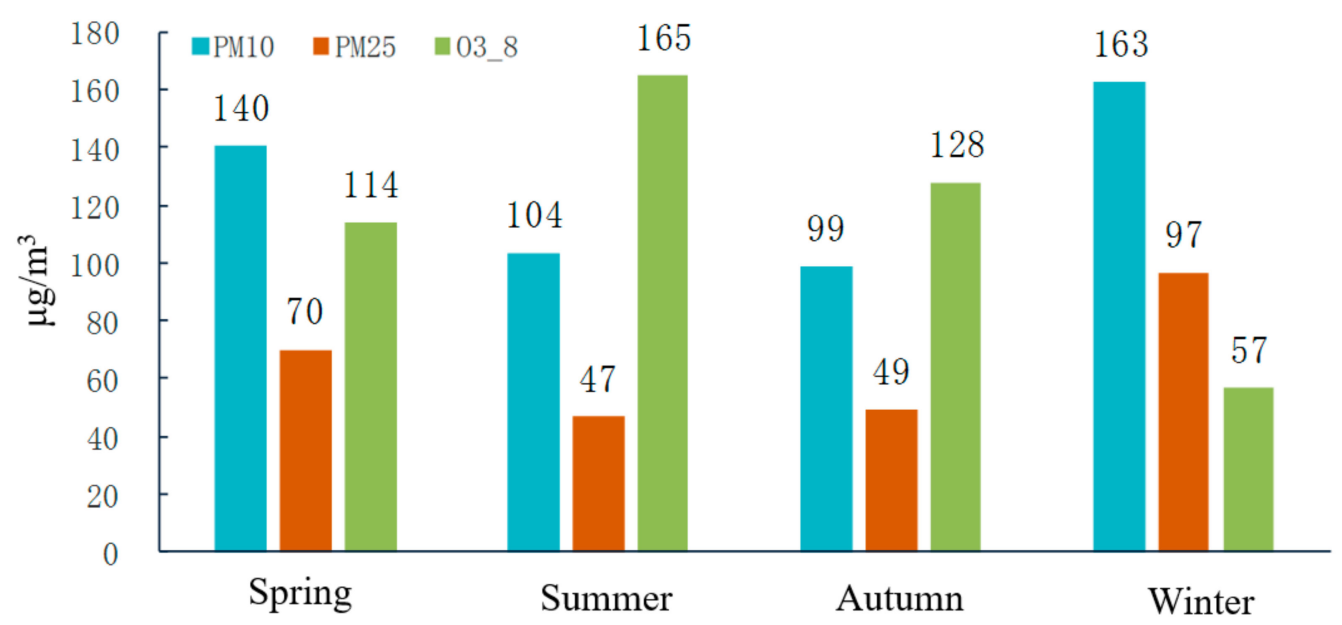

Figure 7. Seasonal concentration characteristics of the primary pollutants.
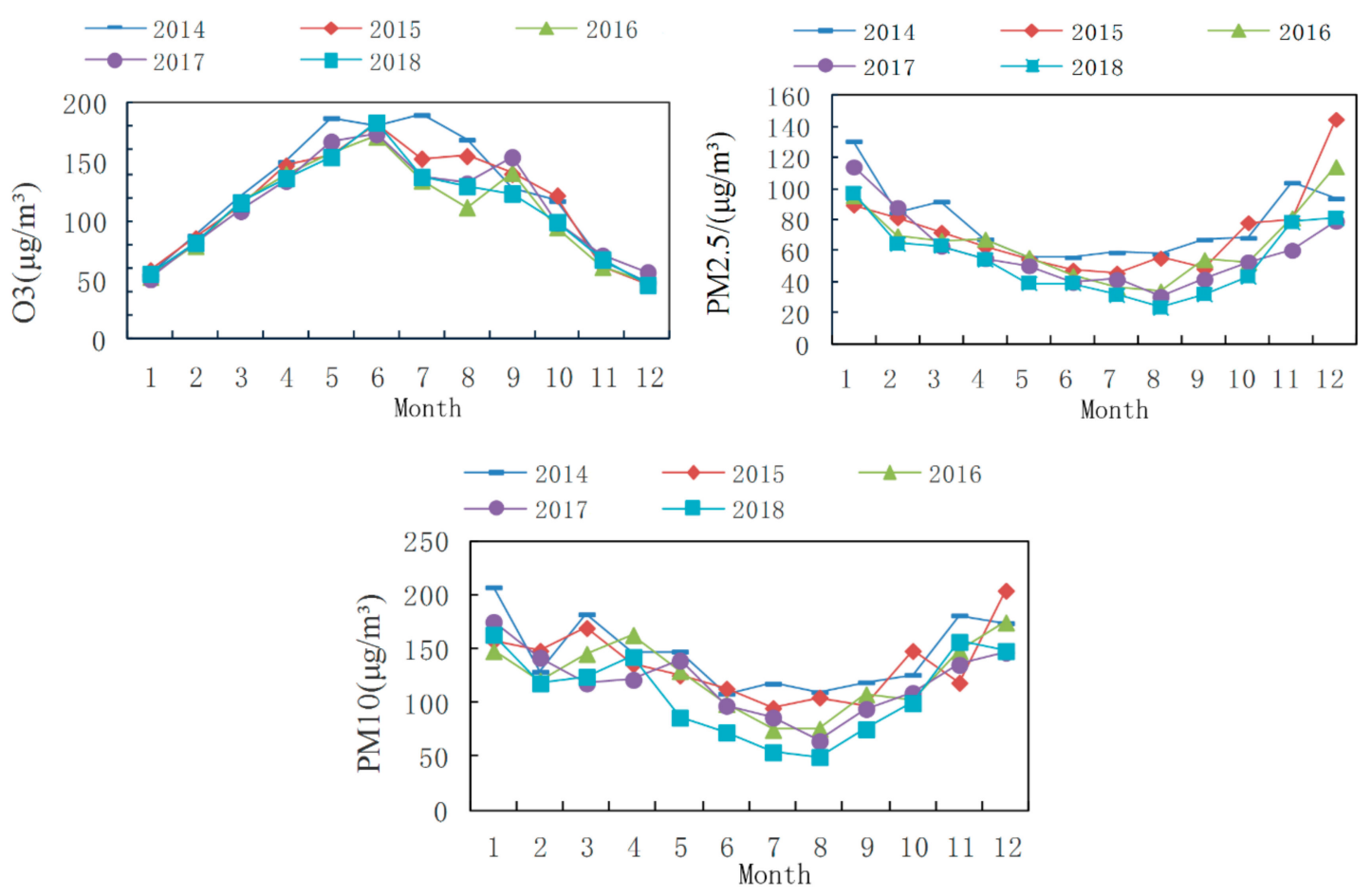

Figure 8. Monthly characteristics of the primary pollutants from 2014-2018. 
The $\mathrm{O}_{3}$ concentration in Weifang increases in summer, probably because intense sunshine, prolonged solar radiation, and high temperatures during summer are conducive to more intense photosynthesis, thereby promoting the conversion of nitrogen oxides and volatile organic pollutants into $\mathrm{O}_{3}[26,30]$. The $\mathrm{O}_{3}$ concentration is significantly and positively correlated with the air temperature. In contrast, the high regional temperatures, stronger solar radiation, rapid surface convection, and increased precipitation and vegetation coverage in Summer facilitate air movement and thus promote diffusion and dilution of atmospheric $\mathrm{PM}$, such as $\mathrm{PM}_{2.5}$ and $\mathrm{PM}_{10}$ [31]. In addition, weak regional convection and a relatively stable atmosphere in Winter easily result in inversion layers, and this situation is not conducive to the diffusion of atmospheric PM. Moreover, both central heating and greater energy consumption in Winter give rise to a higher $\mathrm{PM}_{2.5}$ concentration.

\subsubsection{Daily Characteristics}

The Fourier fitting method is used to conduct Fourier approximation analysis of the characteristics of the daily average concentrations of the primary pollutants in Weifang from 2014-2018. The Fourier approximation functions of the AQI and the primary pollutants, $\mathrm{O}_{3}, \mathrm{PM}_{10}$, and $\mathrm{PM}_{2.5}$, are shown in Figure 9 (multiple determination coefficient R2 > 0.99).
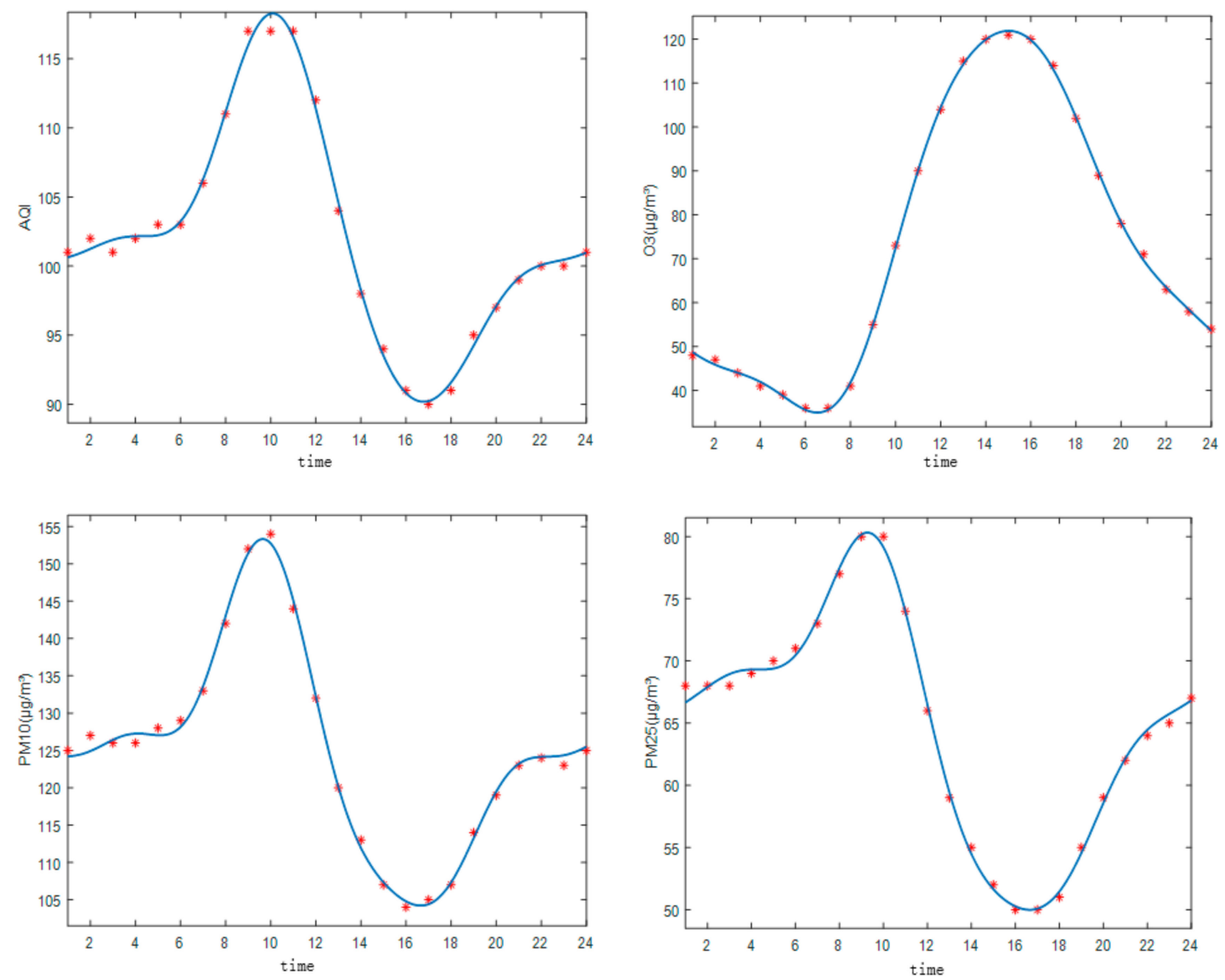

Figure 9. Fitting curves of the AQI and major pollutant concentration.

As illustrated in Figure 9, the concentrations of both $\mathrm{PM}_{10}$ and $\mathrm{PM}_{2.5}$ peak at approximately 09:00. The peak concentrations are $153 \mu \mathrm{g} / \mathrm{m}^{3}$ and $82 \mu \mathrm{g} / \mathrm{m}^{3}$, respectively. The troughs are observed at approximately 16:00, probably because human activities become less intense at this time, leading to a reduction in atmospheric PM emissions. Furthermore, there is sufficient time for most pollutants to gradually diffuse. This finding is partly in agreement with previous studies of Wang et al. [32], who showed that the daily average value of $\mathrm{PM}_{2.5}$ concentration peaked at 10:00 and the valley occurred 
at 16:00. In contrast, the characteristics of $\mathrm{O}_{3}$ are opposite to those of the AQI, $\mathrm{PM}_{10}$, and $\mathrm{PM}_{2.5}$. The minimum $\mathrm{O}_{3}$ concentration of $40 \mu \mathrm{g} / \mathrm{m}^{3}$ is observed from 06:00-07:00; then, the concentration increases rapidly and reaches its maximum of $123 \mu \mathrm{g} / \mathrm{m}^{3}$ from 14:00-16:00, suggesting that the $\mathrm{O}_{3}$ concentration is positively correlated with the solar radiation intensity. In general, the daily characteristics of $\mathrm{PM}_{2.5}, \mathrm{PM}_{10}$, and $\mathrm{AQI}$ are greatly similar, but the AQI shows some delay compared to $\mathrm{PM}_{2.5}$ and $\mathrm{PM}_{10}$.

\subsection{Spatial Characteristics of the Primary Pollutants that Affect the AQI}

The spatial distribution of the annual average concentrations of the primary pollutants is shown in Figure 10. One should note that the county/district air pollution level is represented by the average of points where concentrations are monitored within the area, which may lead to extrapolation errors/bias. However, generally speaking, these statistical results provide a way to understand the spatial distribution characteristics of regional air pollution, which support the local government decision-making for environmental governance.

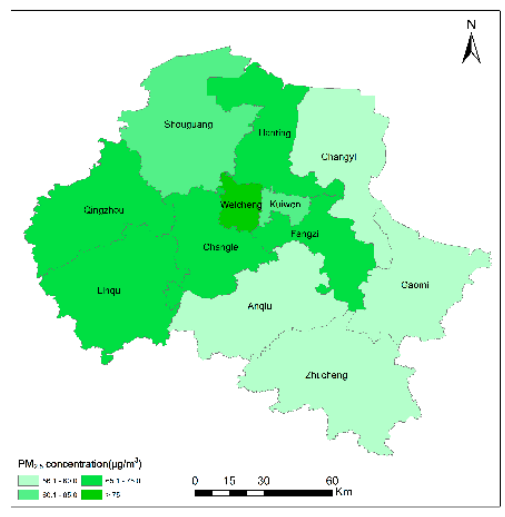

(A) $\mathrm{O}_{3}$

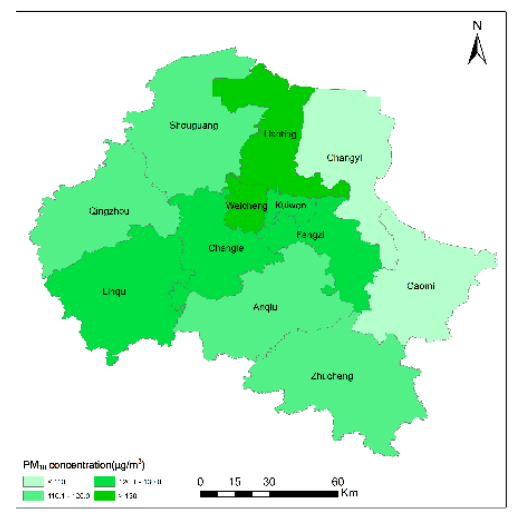

(B) $\mathrm{PM}_{10}$

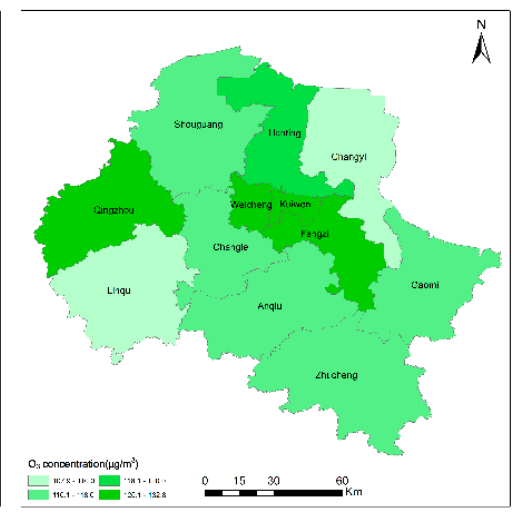

(C) $\mathrm{PM}_{2.5}$

Figure 10. Spatial distribution of the primary pollutant concentrations in Weifang. (A) $\mathrm{O}_{3}$ concentration; (B) $\mathrm{PM}_{10}$ concentration; (C) $\mathrm{PM}_{2.5}$ concentration.

In general, the $\mathrm{O}_{3}$ concentration is high in the central region of the city and low in the rural areas. In particular, the concentrations in both Weicheng District and Kuiwen District exceed $130 \mu \mathrm{g} / \mathrm{m}^{3}$. The reason may be that the $\mathrm{O}_{3}$ concentration is greatly influenced by the intensive human activities in the central region, resulting in significant ozone pollution effects. According to the daily characteristics of the $\mathrm{O}_{3}$ concentration, the government can focus on the central region and take proper measures to strictly control volatile organic pollutant and vehicle emissions during the period when the $\mathrm{O}_{3}$ concentration peaks (approximately 15:00) [33].

The $\mathrm{PM}_{10}$ concentration presents a west-high, east-low trend and lies between $90 \mu \mathrm{g} / \mathrm{m}^{3}$ and $140 \mu \mathrm{g} / \mathrm{m}^{3}$. The concentrations in the west basically exceed $120 \mu \mathrm{g} / \mathrm{m}^{3}$, while those in the southeast are normally approximately $110 \mu \mathrm{g} / \mathrm{m}^{3}$. In particular, the highest concentration of $135.14 \mu \mathrm{g} / \mathrm{m}^{3}$ is observed in the Weicheng District. The concentrations in the Hanting District and Linqu are $131.02 \mu \mathrm{g} / \mathrm{m}^{3}$ and $129.33 \mu \mathrm{g} / \mathrm{m}^{3}$, respectively. Gaomi and Changyi have the lowest concentrations of $103.30 \mu \mathrm{g} / \mathrm{m}^{3}$ and $106.75 \mu \mathrm{g} / \mathrm{m}^{3}$, respectively.

The $\mathrm{PM}_{2.5}$ concentration in Weifang shares similar spatial characteristics with the $\mathrm{PM}_{10}$ concentration, with higher values in the west compared to the southwest. The regional average concentration falls within the range of $55-85 \mu \mathrm{g} / \mathrm{m}^{3}$. Specifically, the highest $\mathrm{PM}_{2.5}$ concentration of $83.38 \mu \mathrm{g} / \mathrm{m}^{3}$ is measured in the Weicheng District, followed by that in Qingzhou $\left(74.22 \mu \mathrm{g} / \mathrm{m}^{3}\right)$. Anqiu and Changyi have the lowest concentrations of $58.24 \mu \mathrm{g} / \mathrm{m} 3$ and $56.13 \mu \mathrm{g} / \mathrm{m}^{3}$, respectively.

There may be two reasons for the spatial characteristics of $\mathrm{PM}_{2.5}$ and $\mathrm{PM}_{10}$. One reason is the topography of the region: the southern part of Weifang consists mostly of low hills with extensive 
vegetation, which can effectively adsorb atmospheric particulates and reduce the amount of ground aerosols reaching the atmosphere, which thereby lowers the PM concentrations [20]; in contrast, the western Weifang area includes Shouguang and Qingzhou counties, and is adjacent to Zibo City, a heavy industrial city with more severe air pollution. Substantial air pollutants and toxic particles from Zibo City can be transported to the western areas, resulting in an intense air pollution effect. The other reason is related to the rapid population growth in the western cities, such as Linqu and Qingzhou. The population densities in these cities are higher, resulting in increased residential emissions of atmospheric pollutants and therefore higher regional PM concentrations [34].

\subsection{Correlation Between the Primary Pollutants and Meteorological Factors}

The above analysis shows that $\mathrm{PM}_{10}$ and $\mathrm{PM}_{2.5}$ have similar characteristics, so in this section, the correlations among $\mathrm{PM}_{2.5}$, which represents $\mathrm{PM}_{10}$, and $\mathrm{O}_{3}$ and meteorological factors are analyzed.

Figure 11 shows the correlations of the $\mathrm{PM}_{2.5}$ concentration with meteorological factors. As illustrated in panel $\mathrm{A}$, the $\mathrm{PM}_{2.5}$ concentration has a negative relationship with the temperature. The $\mathrm{PM}_{2.5}$ concentration is higher from $-6-\left(-5^{\circ} \mathrm{C}\right)$, when PM pollution occurs frequently. It can be deduced that this temperature range is the most conducive to $\mathrm{PM}_{2.5}$ generation. In addition, this temperature range is not conducive to pollutant diffusion, easily leading to accumulation. When the temperature exceeds $15^{\circ} \mathrm{C}$, the $\mathrm{PM}_{2.5}$ concentration decreases, possibly because high temperatures and abundant precipitation in Summer help to effectively wash away pollutants. As shown in panel B, the $\mathrm{PM}_{2.5}$ concentration also has a negative relationship with the wind speed. More specifically, when the wind speed is $0-4 \mathrm{~m} / \mathrm{s}$, the frequency of serious $\mathrm{PM}_{2.5}$ pollution is the highest. However, when the wind speed is higher than $4 \mathrm{~m} / \mathrm{s}$, the severe pollution cases decrease, suggesting that at such wind speeds, winds facilitate diffusion and dilution of atmospheric pollutants more effectively, while winds slower than $4 \mathrm{~m} / \mathrm{s}$ can weaken these effects. In addition, winds slower than $4 \mathrm{~m} / \mathrm{s}$ will entrain dust, leading to increased pollutant concentrations in certain localities. Hence, at wind speeds of $0-2 \mathrm{~m} / \mathrm{s}$, effective measures should be taken in advance to avoid exacerbated air pollution due to PM diffusion. These findings echo many previous studies which showed a negative correlation between the temperature, wind and the air pollution [2]. However, the same finding was not observed in the study of Zhan et al. [9], who presented a positive relationship between AQI and wind speed and reported that both downwind areas and dust storm-prone areas are likely to suffer serious air pollution by increasing wind speed.
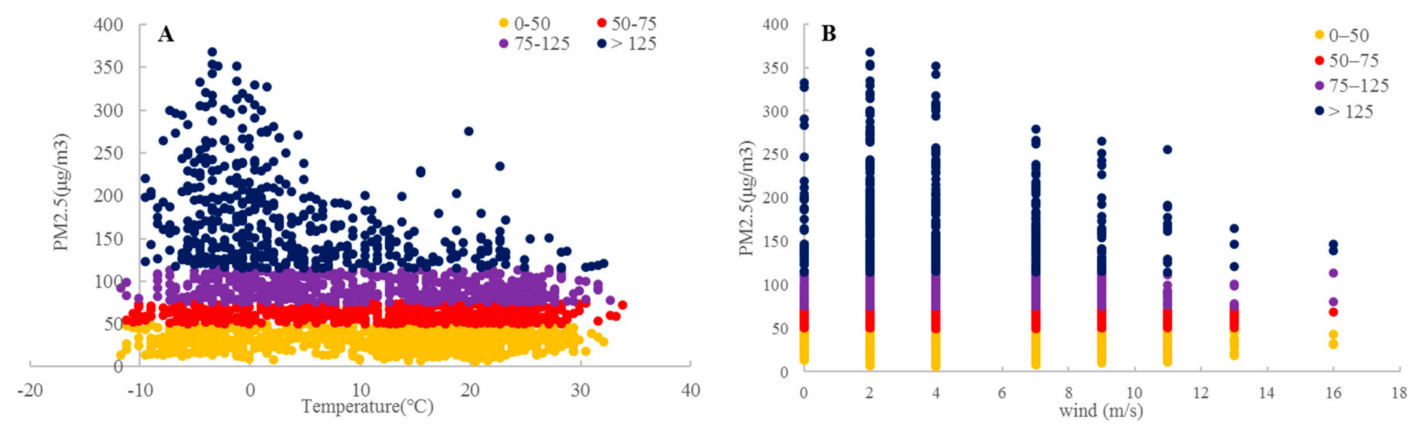

Figure 11. Correlations between the $\mathrm{PM}_{2.5}$ concentration and meteorological factors. (A) temperature; (B) wind speed.

Figure 12 shows the correlations of the $\mathrm{O}_{3}$ concentration with meteorological factors. In contrast to $\mathrm{PM}_{2.5}$, the $\mathrm{O}_{3}$ concentration has a positive relationship with the temperature. The $\mathrm{O}_{3}$ concentration is higher at approximately $25^{\circ} \mathrm{C}$. The higher the temperature, the higher the $\mathrm{O}_{3}$ concentration. Similar to $\mathrm{PM}_{2.5}$, the $\mathrm{O}_{3}$ concentration has a negative relationship with the wind speed. When the wind speed exceeds $8 \mathrm{~m} / \mathrm{s}, \mathrm{O}_{3}$ pollution decreases. Compared with the correlation between the $\mathrm{PM}_{2.5}$ concentration and wind speed, the relationship between the $\mathrm{O}_{3}$ concentration and wind speed is not 
significant. The findings in this study can support the results of some previous studies in the terms of quantitative analysis.
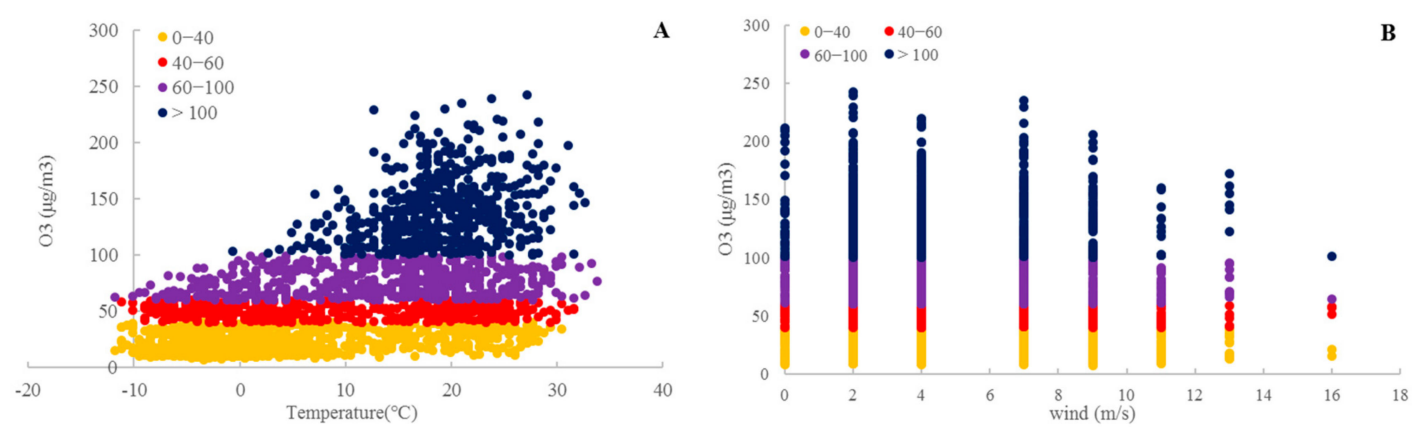

Figure 12. Correlations between the $\mathrm{O}_{3}$ concentration and meteorological factors. (A) temperature; (B) wind speed.

\subsection{Policy Implications}

Some effective policy advice based on the findings of this study is presented to reduce air pollution. First, the main primary pollutants influencing AQI in Weifang are $\mathrm{O}_{3}, \mathrm{PM}_{10}$ and $\mathrm{PM}_{2.5}$, which should receive more attention by the government. According to their spatio-temporal characteristics, more emphasis should be placed on mitigating $\mathrm{PM}_{10}$ and $\mathrm{PM}_{2.5}$ in winter and in western regions, and $\mathrm{O}_{3}$ pollution in Summer, which is mainly distributed in central areas.

Second, $\mathrm{O}_{3}$ is the primary pollutant influencing AQI in Weifang, which is not a special case. Studies in Shenzhen [33] and Beijing [27] also showed similar conclusions. With more efforts were devoted to control the pollution of particulate matter, such as $\mathrm{PM}_{2.5}$, near-surface ozone will be another key factor affecting China's air quality after particulate matter. However, the attention to ozone in China is still in its infancy. The Chinese government should pay more attention to ozone pollution. For instance, the $\mathrm{O}_{3}$ concentration is closely related to intense human activities and temperature, which are usually high in Summer and at approximately 15:00 daily, and initiatives such as strictly controlling volatile organic pollutants and vehicle emissions should be implemented by the government in the central region during the period when $\mathrm{O}_{3}$ concentration peaks (15:00 pm).

Third, serious air pollution (such as $\mathrm{PM}_{10}$ and $\mathrm{PM}_{2.5}$ ) occurred in western Weifang (such as Linqu and Qingzhou) due to two reasons. One is related to the local high population density, the other is correlated with the air pollution transportation from adjacent areas. Zibo City is located on the western side of Weifang City, a heavy industrial city with more severe air pollution. The air pollutants from Zibo City can be transported to the western areas in Weifang. The government should promote the improvement of industrial structure, implement and set pollutant emission standards and use clean energy to decrease air pollution. Additionally, this result also implies that it is a global problem for air pollution mitigation, and implying that is significant for regional cooperation [35]. When formulating measures to prevent and control air pollution, attention should be paid to the interaction between cities and surrounding areas, and the joint prevention and cooperation between regions should be strengthened.

Finally, vegetation plays an important role in air quality. Government can plant more trees in heavily polluted areas, which can significantly increase the surface leaf area and relative humidity, achieve pollutant adsorption and a dilution effect, and effectively reduce air pollution [24].

\section{Conclusions}

Using hourly ground-monitoring data from 2014-2018 in Weifang City, this study examined the temporal and spatial characteristics of the AQI in Weifang along with its primary pollutants $\left(\mathrm{O}_{3}, \mathrm{PM}_{10}\right.$ and $\mathrm{PM}_{2.5}$ ) and analyzed the relationships between the major pollutants of the city and meteorological factors. The major conclusions are as follows. 
(a) The results showed that the AQI in Weifang was higher than 100 from 2014-2017, and decreased significantly since 2017. In the last five years, the annual average proportion of days with excellent and good air quality has increased gradually, reaching $60 \%$ in 2018 , while the number of days with heavy or severe pollution has decreased substantially (declining by $20 \%$ ). This may be because environmental protection actions were implemented under the eight major initiatives in 2017, which are beneficial for air pollution mitigation.

(b) The days when AQI > 200 (heavy and severe pollution) are mostly concentrated in January, November, and December. Overall, the AQI is high in Winter and low in Summer. This finding is related to the meteorological conditions and heat-supply during winters.

(c) The primary pollutants in Weifang are $\mathrm{O}_{3}, \mathrm{PM}_{10}$, and $\mathrm{PM}_{2.5}$, accounting for $40.55 \%, 31.23 \%$, and $20.82 \%$, respectively, of the AQI. From 2014-2018, both $\mathrm{PM}_{2.5}$ and $\mathrm{PM}_{10}$ pollution levels significantly decreased, whereas $\mathrm{O}_{3}$ remained basically unchanged. The seasonal and monthly variations in the $\mathrm{PM}_{10}$ and $\mathrm{PM}_{2.5}$ concentrations show $\mathrm{U}$-shaped curves with highs in Winter and at approximately 09:00 daily, while $\mathrm{O}_{3}$ follows an inverted $\mathrm{U}$-shaped curve and is high in Summer at approximately 15:00 daily. This finding infers that near-surface ozone will become another key factor influencing air quality after particulate matter, and more attention should be paid to ozone pollution. The high level of $\mathrm{O}_{3}$ pollution in Summer may be associated with the intense sunshine and prolonged solar radiation. In Summer, initiatives such as strictly controlling volatile organic pollutant and vehicle emissions should be implemented during the period when $\mathrm{O}_{3}$ concentration peaks $(15: 00 \mathrm{pm})$.

(d) Spatially, there is a high $\mathrm{O}_{3}$ pollution level in the central region but a low level in the rural areas, while the $\mathrm{PM}_{10}$ and $\mathrm{PM}_{2.5}$ pollution levels are high in the northwest and low in the southeast. Government can focus on the central region and implement proper measures to strictly control $\mathrm{O}_{3}$ emissions while preventing PM pollution in northwestern regions.

(e) The $\mathrm{PM}_{2.5}$ concentration in Weifang is negatively correlated with the air temperature and wind speed, while the $\mathrm{O}_{3}$ concentration is positively correlated with the air temperature but negatively correlated with the relative humidity and wind speed. This is consistent with the findings that the $\mathrm{O}_{3}$ pollution level is high in Summer.

This paper is significant in terms of the in-depth understanding of the spatiotemporal characteristics of air quality and the primary pollutants that affect the AQI in Weifang in recent years. The study provides critical insights into future urban development and pollution control. However, this study has limitations. For instance, the county/district air pollution level is represented by the average of point-monitored concentrations within the area, which may lead to extrapolation errors/bias. Furthermore, air quality is affected by various factors, such as weather and human activities, and there is a lack of quantitative analysis on air quality and other influential factors in this paper. There is a need for future work to combine remote-sensed data and ground-monitored data to control extrapolation errors/bias and to explore relationships between other driving factors and air pollutants for more urban sites.

Author Contributions: Conceptualization: C.L.; methodology: C.L., Z.M., and Z.D.; software: L.Y.; validation: C.L. and Z.D.; formal analysis: L.Y.; investigation: L.Y. and Z.M.; resources: C.L.; data curation: L.Y. and Z.D.; writing - original draft preparation: Z.D. and L.Y.; writing-review and editing: C.L. and Z.D.; visualization: C.L. and Z.D.; supervision: C.L. and Z.D.; project administration: C.L.; funding acquisition: C.L.

Funding: This research was funded by the National Key Research and Development Program of China (Grant No. 2018YFB2100700) and National Natural Science Foundation of China (41871375).

Conflicts of Interest: The authors declare no conflict of interest. 


\section{Abbreviation}

$\begin{array}{ll}\mathrm{AQI} & \text { Air Quality Index } \\ \mathrm{PM}_{10} & \text { Particles with aerodynamic diameter } \leq 10 \mu \mathrm{m} \\ \mathrm{PM}_{2.5} & \text { Particles with aerodynamic diameter } \leq 2.5 \mu \mathrm{m} \\ \mathrm{NO}_{2} & \text { Nitrogen Dioxide } \\ \mathrm{SO}_{2} & \text { Sulfur Dioxide } \\ \mathrm{CO} & \text { Carbon Monoxide } \\ \mathrm{AOD} & \text { Aerosol Optical Depth } \\ \mathrm{IAQI} & \text { Individual Air Quality Index } \\ \mathrm{IAQI}_{\mathrm{p}} & \text { Air quality sub-index for pollutant } \mathrm{p} \\ \mathrm{C}_{\mathrm{p}} & \text { Concentration of pollutant } \mathrm{p} \\ \mathrm{C}_{\mathrm{Lo}} & \text { Concentration breakpoint that is } \leq \mathrm{C} \\ \mathrm{C}_{\mathrm{Hi}} & \text { Concentration breakpoint that is } \geq \mathrm{C} \\ \mathrm{IAQI}_{\mathrm{Lo}} & \text { Index breakpoint corresponding to } \mathrm{C}_{\mathrm{Lo}} \\ \mathrm{IAQI}_{\mathrm{Hi}} & \text { Index breakpoint corresponding to } \mathrm{C}_{\mathrm{Hi}} \\ \mathrm{CAAQS} & \text { Chinese Ambient Air Quality Standards }\end{array}$

\section{References}

1. He, J.H.; Ding, S.; Liu, D.F. Exploring the spatiotemporal pattern of $\mathrm{PM}_{2.5}$ distribution and its determinants in Chinese cities based on a multilevel analysis approach. Sci. Total Environ. 2019, 659, 1513-1525. [CrossRef]

2. Xiao, K.; Wang, Y.K.; Wu, G.; Fu, B.; Zhu, Y. Spatiotemporal Characteristics of Air Pollutants $\left(\mathrm{PM}_{10}, \mathrm{PM}_{2.5}\right.$, $\mathrm{SO}_{2}, \mathrm{NO}_{2}, \mathrm{O}_{3}$, and $\mathrm{CO}$ ) in the Inland Basin City of Chengdu, Southwest China. Atmosphere 2018, 9, 74. [CrossRef]

3. Ye, W.F.; Ma, Z.Y.; Ha, X.Z. Spatial-temporal patterns of $\mathrm{PM}_{2.5}$ concentrations for 338 Chinese cities. Sci. Total Environ. 2018, 631, 524-533. [CrossRef] [PubMed]

4. Chow, J.C. Health Effects of Fine Particulate Air Pollution: Lines that Connect. J. Air Waste Manag. Assoc. 2006, 56, 707-708. [CrossRef] [PubMed]

5. Huang, D.; Xu, J.; Zhang, S. Valuing the health risks of particulate air pollution in the Pearl River Delta, China. Environ. Sci. Policy 2012, 15, 38-47. [CrossRef]

6. He, J.Q.; Yu, X.N.; Zhu, B.; Yuan, L.; Ma, J.; Shen, L.; Zhu, J. Characteristics of aerosol extinction and low visibility in haze weather in winter of Nanjing. China Environ. Sci. 2016, 36, 1645-1653.

7. Li, F.; Liu, Y.; Lü, J.J.; Liang, L.; Harmer, P. Ambient air pollution in China poses a multifaceted health threat to outdoor physical activity. J. Epidemiol. Community Health 2015, 69, 201-204. [CrossRef]

8. Chudnovsky, A.A.; Koutrakis, P.; Kloog, I.; Melly, S.; Nordio, F.; Lyapustin, A.; Wang, Y.; Schwartz, J. Fine particulate matter predictions using high resolution Aerosol Optical Depth (AOD) retrievals. Atmos. Environ. 2014, 89, 189-198. [CrossRef]

9. Zhan, D.S.; Kwan, M.P.; Zhang, W.Z.; Yu, X.; Meng, B.; Liu, Q. The driving factors of air quality index in China. J. Clean. Prod. 2018, 197, 1342-1351. [CrossRef]

10. Zhao, S.P.; Yu, Y.; Yin, D.Y.; Qin, D.; He, J.; Li, J.; Dong, L. Two winter $\mathrm{PM}_{2.5}$ pollution types and the causes in the city clusters of Sichuan Basin, Western China. Sci. Total Environ. 2018, 636, 1228-1240. [CrossRef]

11. Yan, D.; Lei, Y.; Shi, Y.; Zhu, Q.; Li, L.; Zhang, Z. Evolution of the spatiotemporal pattern of $\mathrm{PM}_{2.5}$ concentrations in China-A case study from the Beijing-Tianjin-Hebei region. Atmos. Environ. 2018, 183, 225-233. [CrossRef]

12. Hu, J.L.; Wang, Y.G.; Ying, Q.; Zhang, H. Spatial and temporal variability of $\mathrm{PM}_{2.5}$ and $\mathrm{PM}_{10}$ over the North China Plain and the Yangtze River Delta, China. Atmos. Environ. 2014, 95, 598-609. [CrossRef]

13. Chen, T.; He, J.; Lu, X.W.; She, J.; Guan, Z. Spatial and Temporal Variations of $\mathrm{PM}_{2.5}$ and Its Relation to Meteorological Factors in the Urban Area of Nanjing, China. Int. J. Environ. Res. Public Health 2016, $13,921$. [CrossRef]

14. Guan, Q.Y.; Cai, A.; Wang, F.F.; Yang, L.; Xu, C.; Liu, Z. Spatio-temporal variability of particulate matter in the key part of Gansu Province, Western China. Environ. Pollut. 2017, 230, 189-198. [CrossRef]

15. Zhao, D.T.; Chen, H.; Li, X.D.; Ma, X. Air pollution and its influential factors in China's hot spots. J. Clean. Prod. 2018, 185, 619-627. [CrossRef] 
16. Xu, G.; Jiao, L.; Zhang, B.; Zhao, S.; Yuan, M.; Gu, Y.; Liu, J.; Tang, X. Spatial and Temporal Variability of the $\mathrm{PM}_{2.5} / \mathrm{PM}_{10}$ Ratio in Wuhan, Central China. Aerosol Air Qual. Res. 2017, 17, 741-751. [CrossRef]

17. Gao, J.J.; Wang, K.; Wang, Y.; Liu, S.; Zhu, C.; Hao, J.; Liu, H.; Hua, S.; Tian, H. Temporal-spatial characteristics and source apportionment of $\mathrm{PM}_{2.5}$ as well as its associated chemical species in the Beijing-Tianjin-Hebei region of China. Environ. Pollut. 2018, 233, 714-724. [CrossRef]

18. Xiao, C.C.; Chang, M.; Guo, P.; Gu, M.; Li, Y. Analysis of air quality characteristics of Beijing-Tianjin-Hebei and its surrounding air pollution transport channel cities in China. J. Environ. Sci. 2019. [CrossRef]

19. Yang, D.Y.; Lu, D.B.; Xu, J.H.; Ye, C.; Zhao, J.; Tian, G.; Wang, X.; Zhu, N. Predicting spatio-temporal concentrations of $\mathrm{PM}_{2.5}$ using land use and meteorological data in Yangtze River Delta, China. Stoch. Environ. Res. Risk Assess. 2018, 32, 2445-2456. [CrossRef]

20. Li, Y.X.; Dai, Z.X.; Liu, X.L. Analysis of Spatial-Temporal Characteristics of the $\mathrm{PM}_{2.5}$ Concentrations in Weifang City, China. Sustainability 2018, 10, 2906. [CrossRef]

21. Shen, F.; Ge, X.; Hu, J.; Nie, D.; Tian, L.; Chen, M. Air pollution characteristics and health risks in Henan Province, China. Environ. Res. Sci. 2017, 156, 625-634. [CrossRef] [PubMed]

22. Han, J.; Pei, J.; Yin, Y.; Mao, R. Mining Frequent Patterns without Candidate Generation: A Frequent-Pattern Tree Approach. Data Min. Knowl. Discov. 2004, 8, 53-87. [CrossRef]

23. Li, H.; Wang, Y.; Zhang, D.; Zhang, M.; Chang, E.Y. PFP: Parallel FP-growth for query recommendation. In Proceedings of the 2008 ACM Conference on Recommender Systems, Lausanne, Switzerland, 23-25 October 2008; ACM: New York, NY, USA, 2008.

24. Sun, Z.; Zhan, D.; Jin, F. Spatio-temporal Characteristics and Geographical Determinants of Air Quality in Cities at the Prefecture Level and Above in China. Chin. Geogr. Sci. 2019, 29, 316-324. [CrossRef]

25. Wang, S.; Zhou, C.; Wang, Z.; Feng, K.; Hubacek, K. The characteristics and drivers of fine particulate matter $\left(\mathrm{PM}_{2.5}\right)$ distribution in China. J. Clean. Prod. 2017, 142, 1800-1809. [CrossRef]

26. Song, C.; Wu, L.; Xie, Y.; He, J.; Chen, X.; Wang, T.; Lin, Y.; Jin, T.; Wang, A.; Liu, Y.; et al. Air pollution in China: Status and spatiotemporal variations. Environ. Pollut. 2017, 227, 334-347. [CrossRef] [PubMed]

27. Wang, Z.S. Variation of $\mathrm{O}_{3}$ Concentration in Different Regions of Beijing from 2006-2015. Environ. Sci. 2018, $39,1-8$.

28. Cheng, Z.H.; Li, L.S.; Liu, J. Identifying the spatial effects and driving factors of urban $\mathrm{PM}_{2.5}$ pollution in China. Ecol. Indic. 2017, 82, 61-75. [CrossRef]

29. Mi, K.; Zhuang, R.; Zhang, Z.; Gao, J.; Pei, Q. Spatiotemporal characteristics of PM $_{2.5}$ and its associated gas pollutants, a case in China. Sustain. Cities Soc. 2019, 45, 287-295. [CrossRef]

30. Zhao, S.; Yu, Y.; Yin, D.; He, J.; Liu, N.; Qu, J.; Xiao, J. Annual and diurnal variations of gaseous and particulate pollutants in 31 provincial capital cities based on in situ air quality monitoring data from China National Environmental Monitoring Center. Environ. Int. 2016, 86, 92-106. [CrossRef]

31. Fang, C.L.; Wang, Z.B.; Xu, G. Spatial-temporal characteristics of $\mathrm{PM}_{2.5}$ in China: A city-level perspective analysis. J. Geogr. Sci. 2016, 26, 1519-1532. [CrossRef]

32. Wang, Y.; Duan, X.; Wang, L. Spatial-Temporal Evolution of $\mathrm{PM}_{2.5}$ Concentration and Its Socioeconomic Influence Factors in Chinese Cities in 2014-2017. Int. J. Environ. Res. Public Health 2019, 16, 985. [CrossRef]

33. Xie, F.; Li, P.; Zhu, Z. Ozone Pollution characteristics and influence factors in eastern Shenzhen. Environ. Sci. Surv. 2017, 37, 40-49.

34. Li, D.; Zhao, Y.; Wu, R.; Dong, J. Spatiotemporal Features and Socioeconomic Drivers of $\mathrm{PM}_{2.5}$ Concentrations in China. Sustainability 2019, 11, 1201. [CrossRef]

35. Liu, H.; Fang, C.; Zhang, X.; Wang, Z.; Bao, C.; Li, F. The effect of natural and anthropogenic factors on haze pollution in Chinese cities: A spatial econometrics approach. J. Clean. Prod. 2017, 165, 323-333. [CrossRef]

(C) 2019 by the authors. Licensee MDPI, Basel, Switzerland. This article is an open access article distributed under the terms and conditions of the Creative Commons Attribution (CC BY) license (http://creativecommons.org/licenses/by/4.0/). 